\title{
Bulkier glass formability enhanced by minor alloying additions
}

\author{
D. Ma, H. Cao, L. Ding, and Y. A. Chang ${ }^{a}$ \\ Department of Materials Science and Engineering, University of Wisconsin-Madison, \\ 1509 University Avenue, Madison, Wisconsin 53706 \\ K. C. Hsieh \\ Institute of Materials Science and Engineering, Sun Yat Sen University, Kaohsiung 80424, Taiwan, \\ Republic of China \\ Y. Pan \\ Department of Materials Science and Engineering, Southeast University, Nanjing, 210096 \\ People's Republic of China
}

(Received 18 May 2005; accepted 26 August 2005; published online 19 October 2005)

\begin{abstract}
In this study, we present a computational thermodynamic strategy to obtain a minor but optimum amount of additional element into a base alloy to improve its glass-forming ability, through thermodynamically calculating the maximum liquidus depressions caused by various alloying addition (or replacement) schemes. We demonstrate the successful use of $\mathrm{Zr}_{56.2} \mathrm{Cu}_{31.3} \mathrm{Ni}_{4.0} \mathrm{Al}_{8.5}$ as the base alloy with the addition of $4.9 \% \mathrm{Ti}$, by observing a significant increase in the glass-forming ability of more than $100 \%$ in terms of the diameter of the glass formed from the base alloy to the one with the addition of $4.9 \% \mathrm{Ti}$. The approach presented here can be considered as a universal method to synthesize novel and bulkier metallic glasses not only of scientific interest but also potential technological applications. (C) 2005 American Institute of Physics.

[DOI: $10.1063 / 1.2115074]$
\end{abstract}

In the year 2004, we witnessed encouraging discoveries of centimeter-sized bulk metallic glasses (BMGs) based on ordinary transition metals, such as $\mathrm{Cu}$ (Ref. 1) and Fe (Ref. $2)$. The key for the success is attributed to the addition of small amounts of yttrium $(<5 \%$, atomic percent hereafter $)$ into known glass-forming alloys, i.e., $\mathrm{Cu}_{46} \mathrm{Zr}_{47} \mathrm{Al}_{7}$ and $\mathrm{Fe}_{44.3} \mathrm{Cr}_{5} \mathrm{Co}_{5} \mathrm{Mo}_{12.8} \mathrm{Mn}_{11.2} \mathrm{C}_{15.8} \mathrm{~B}_{5.9}$, respectively. This success has provided a fresh impetus to the idea that micro- or minor alloying represents an effective way to develop novel bulkier metallic glasses. However, due to the complex nature of the multicomponent interactions involved, the underlying mechanism upon the enhancement of glass-forming ability (GFA) by minor alloying still remains a puzzling mystery. It thus becomes difficult to identify the optimum amount of a potential element, a priori, for improving the GFA of a known glass-forming alloy. Neither the recent compelling structural model proposed by Miracle, ${ }^{3}$ nor current atomistic simulation, such as reverse Monte Carlo and molecular dynamics simulation, is able to make such predictions. ${ }^{4,5}$ Here, using $\mathrm{Al}-\mathrm{Cu}-\mathrm{Ni}-\mathrm{Zr}-\mathrm{Ti}$ as a model system, we present a robust computational thermodynamic approach to obtain multicomponent phase diagrams; ${ }^{6}$ on the basis of which, we are able to formulate a practically useful strategy for pinpointing bulkier glass-forming compositions of $\mathrm{Al}-\mathrm{Cu}-\mathrm{Ni}-\mathrm{Zr}$ with optimum Ti-alloying additions.

A strong indication drawn from the aforementioned experimental works ${ }^{1,2}$ is that the Y-enhanced GFA of the $\mathrm{Cu}-$ and Fe-based alloys is accompanied by a substantial depression in the liquidus temperature caused by the addition of $\mathrm{Y}$, and the bulkiest Y-alloyed BMGs are those possessing the deepest liquidus depressions compared with the base alloys. These findings are in accord with the known GFA criteria, such as $T_{r g}\left(=T_{g} / T_{l}\right.$, where $T_{g}$ is the glass transition temperature and $T_{l}$ is the liquidus temperature $)$ and $\gamma\left(=T_{x} /\left(T_{l}+T_{g}\right)\right.$,

\footnotetext{
${ }^{a)}$ Electronic mail: chang@engr.wisc.edu
}

where $T_{x}$ is the temperature of the onset of crystallization), both of which indicate that decreasing the liquidus temperature facilitates easier glass formation. ${ }^{7,8}$ In thermodynamics, the existence of an alloy liquid toward lower temperatures is a manifestation of its increasing thermodynamic stability when compared with its competing crystalline phases as the temperature is lowered. Although this is a necessary but not a sufficient condition, decreasing temperature increases the liquid's viscosity (with corresponding decreases in its diffusivity). ${ }^{9}$ This in turn, kinetically, also favors glass formation. Thus, in this letter, we use the liquidus temperature (or depression) of an alloy as an indicator for its glassforming tendency, ${ }^{1-3,7-9}$ which can be readily obtained from thermodynamically calculated multicomponent phase diagrams.

Figure 1 shows a calculated isopleth of the quinary Al$\mathrm{Cu}-\mathrm{Ni}-\mathrm{Zr}-\mathrm{Ti}$ phase diagram with $8.5 \% \mathrm{Al}, 31.3 \% \mathrm{Cu}$, and $4.0 \% \mathrm{Ni}$, using a thermodynamic description of $\mathrm{Al}-\mathrm{Cu}-\mathrm{Ni}-$ $\mathrm{Zr}$-Ti developed by us. ${ }^{6,10}$ The concentration of $\mathrm{Ti}$ varies from 0 to $15.0 \%$ with a corresponding concentration of $\mathrm{Zr}$ from $56.2 \%$ to $41.2 \%$. In other words, we use Ti to partially replace $\mathrm{Zr}$ in a quaternary base alloy $\mathrm{Zr}_{56.2} \mathrm{Cu}_{31.3} \mathrm{Ni}_{4.0} \mathrm{Al}_{8.5}$. We identified this quaternary alloy to be a bulk glass-forming alloy (with a critical casting diameter for glass formation of $\sim 6 \mathrm{~mm}$ ) based on the calculated low-lying liquidus surface of the quaternary $\mathrm{Zr}-\mathrm{Cu}-\mathrm{Ni}-\mathrm{Al}$ system. ${ }^{11}$ As shown in this isopleth, the calculated liquidus at the origin of the compositional coordinate, i.e., the base alloy $\mathrm{Zr}_{56.2} \mathrm{Cu}_{31.3} \mathrm{Ni}_{4.0} \mathrm{Al}_{8.5}$, decreases rapidly to a minimum at about $4.9 \% \mathrm{Ti}$ and then increases again. Thus, the liquidus depression reaches a maximum of $102 \mathrm{~K}$ at $4.9 \% \mathrm{Ti}$ replacement. Accordingly, a series of alloys of $\mathrm{Zr}_{56.2-x} \mathrm{Ti}_{x} \mathrm{Cu}_{31.3} \mathrm{Ni}_{4.0} \mathrm{Al}_{8.5}$ with values of $x$ varying from 0 to 12 , were prepared with the expectation that the alloy with $4.9 \% \mathrm{Ti}$ would exhibit the highest GFA.

Ingots of alloys $\mathrm{Zr}_{56.2-x} \mathrm{Ti}_{x} \mathrm{Cu}_{31.3} \mathrm{Ni}_{4.0} \mathrm{Al}_{8.5} \quad(x=0-12)$ were made by arc melting mixtures of high-purity $\mathrm{Zr}, \mathrm{Ti}, \mathrm{Cu}$, 


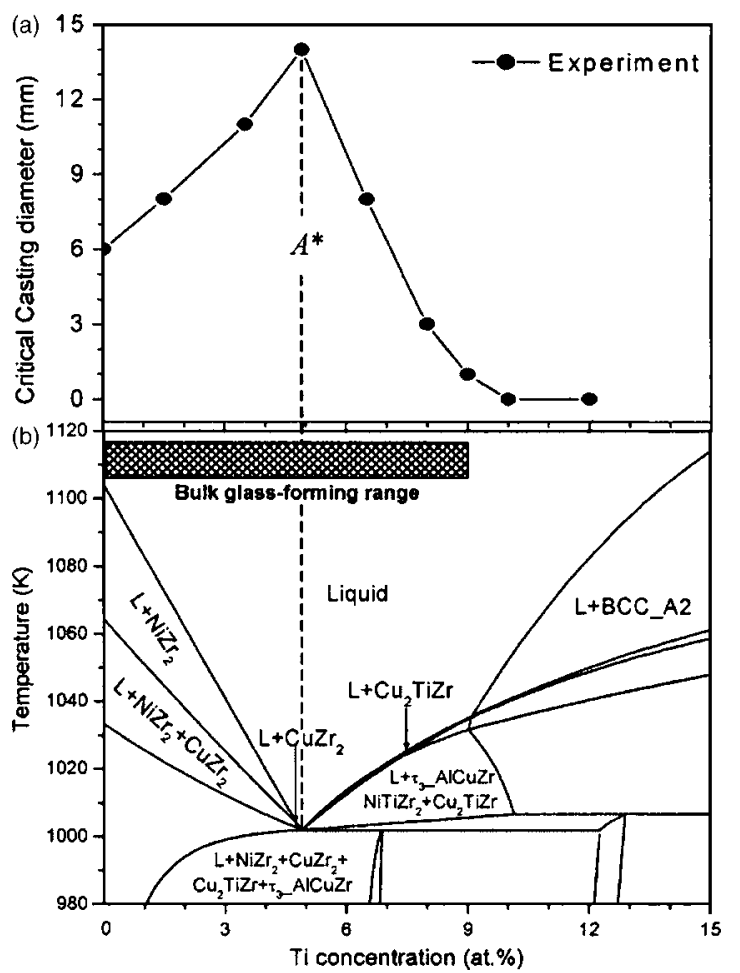

FIG. 1. (a) The critical casting diameter as a function of Ti concentration in a series of alloys $\mathrm{Zr}_{56.2-x} \mathrm{Ti}_{x} \mathrm{Cu}_{31.3} \mathrm{Ni}_{4.0} \mathrm{Al}_{8.5}\left(x=0-12\right.$ ), showing $\mathrm{A}^{*}$ (containing $4.9 \% \mathrm{Ti}$ ) is the bulkiest glass-forming alloy; (b) The calculated isopleth, i.e., a temperature versus $\mathrm{Ti}$ concentration section, obtained by maintaining the compositions of $\mathrm{Cu}, \mathrm{Ni}$, and $\mathrm{Al}$ fixed at $31.3 \%, 4.0 \%$, and $8.5 \%$, respectively. The shaded area denotes the experimentally observed bulk glassforming range.

$\mathrm{Ni}$ and Al (Zr: 99.95\%; the rest: $99.99+\%)$ pieces in a Tigettered argon atmosphere. Each alloy ingot was then remelted and cast, under a purified $\mathrm{Ar}$ (or He) atmosphere, into a copper mold with an internal cylindrical cavity of diameters ranging from 1 to $14 \mathrm{~mm}$. The amorphous nature of the as-cast rods was examined by analyzing the central part of their cross sections using x-ray Diffractometry (XRD) with $\mathrm{Cu} \mathrm{K} \alpha$ radiation. The glass transition and crystallization behaviors of these alloys upon reheating were characterized using a Perkin-Elmer DSC7 (Differential Scanning Calorimeter) at a heating rate of $20 \mathrm{~K} / \mathrm{min}$.

Figure 2 shows the XRD patterns obtained from as-cast

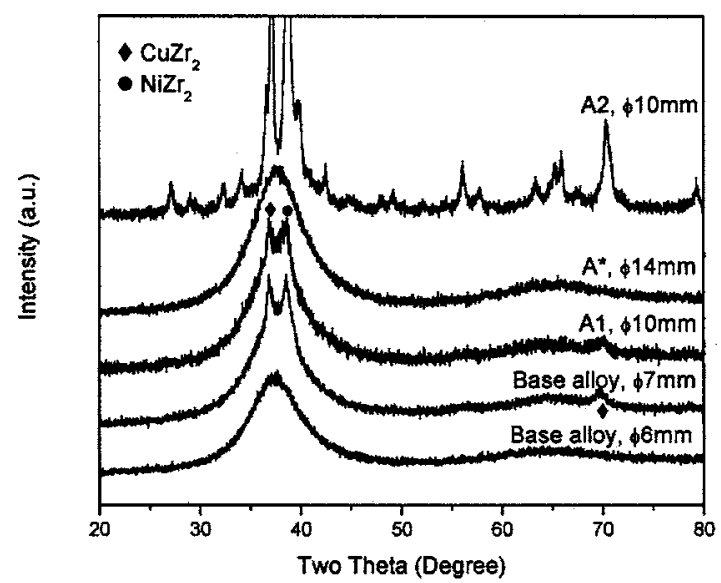

FIG. 2. XRD patterns obtained from as-cast rods with diameters of 6 and $7 \mathrm{~mm}$ for the base alloy $\left(\mathrm{Zr}_{56.2} \mathrm{Cu}_{31.3} \mathrm{Ni}_{4.0} \mathrm{Al}_{8.5}\right), 10 \mathrm{~mm}$ for alloy A1 (containing $1.5 \% \mathrm{Ti}$ ), $14 \mathrm{~mm}$ for alloy $\mathrm{A}^{*}$ (containing $4.9 \% \mathrm{Ti}$ ) and $10 \mathrm{~mm}$ for alloy A2 (containing 6.5\% Ti). alloy B4 $\left(\mathrm{Zr}_{56.2} \mathrm{Cu}_{31.3} \mathrm{Ni}_{40} \mathrm{Al}_{7.2} \mathrm{Ti}_{1.3}\right)$.
Downloy A2 (containing 6.5\% Ti).

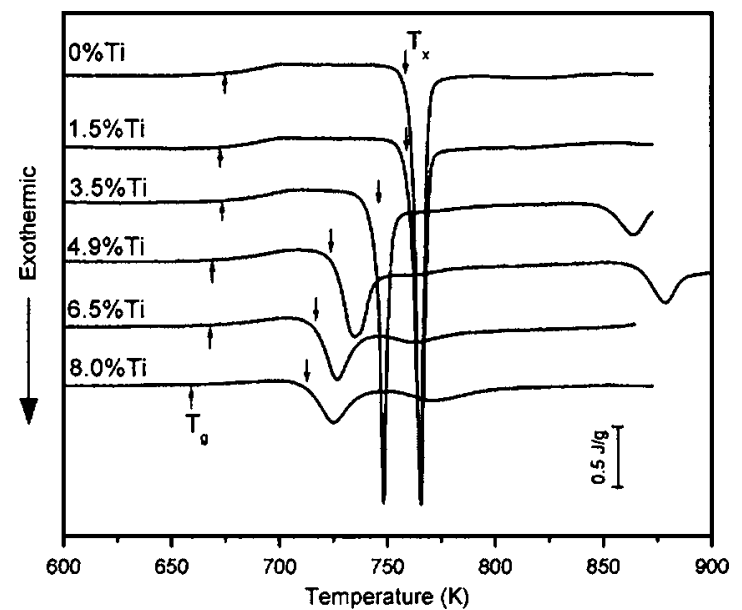

FIG. 3. DSC traces of a series of alloys $\mathrm{Zr}_{56.2-x} \mathrm{Ti}_{x} \mathrm{Cu}_{31.3} \mathrm{Ni}_{4.0} \mathrm{Al}_{8.5}(x=0,1.5$, $3.5,4.9,6.5$, and 8.0), with the specimens being taken from $2 \mathrm{~mm}$ as-cast rods of these alloys. The upward arrows refer to the glass transition temperatures $\left(T_{g}\right)$ and the downward ones denote the onset crystallization temperatures $\left(T_{x}\right)$.

rods of four representative alloys with various additions of Ti, i.e., $\mathrm{Zr}_{56.2-x} \mathrm{Ti}_{x} \mathrm{Cu}_{31.3} \mathrm{Ni}_{4.0} \mathrm{Al}_{8.5}$ where $x=0$, 1.5, 4.9, and 6.5 , being denoted here as the base alloy, A1, $\mathrm{A}^{*}$, and A2, respectively. For the Ti-free base alloy (i.e., $\mathrm{Zr}_{56.2} \mathrm{Cu}_{31.3} \mathrm{Ni}_{4.0} \mathrm{Al}_{8.5}$ ), the pattern of its $6 \mathrm{~mm}$ diameter sample exhibits a series of broad diffraction maxima characteristic of a monolithic amorphous phase, but several sharp crystalline peaks (corresponding to $\mathrm{CuZr}_{2}$ and $\mathrm{NiZr}_{2}$ ) are visible in the pattern of its $7 \mathrm{~mm}$ sample, indicating that the critical casting diameter $\left(d_{\max }\right)$ of the base alloy is $\sim 6 \mathrm{~mm}$. In contrast, for alloy $\mathrm{A}^{*}$ (containing $4.9 \% \mathrm{Ti}$ ), there are no crystalline peaks discernible in the main amorphous halos in the XRD pattern taken from its $14 \mathrm{~mm}$ sample, demonstrating that the critical casting diameter of alloy $\mathrm{A}^{*}$, at least, doubles that of the base alloy. Although a small amount of the Ti addition $(<4.9 \%)$ tends to improve the GFA, the critical casting diameters are found all below $12 \mathrm{~mm}$; a typical XRD pattern is shown for a $10 \mathrm{~mm}$ sample of alloy A1 (containing $1.5 \% \mathrm{Ti}$ ), which consists of sharp crystalline peaks superimposed on the pronounced amorphous halo, indicative of a partially amorphous structure. Meanwhile excessive addition of $\mathrm{Ti}(>4.9 \%)$ is found to severely deteriorate the

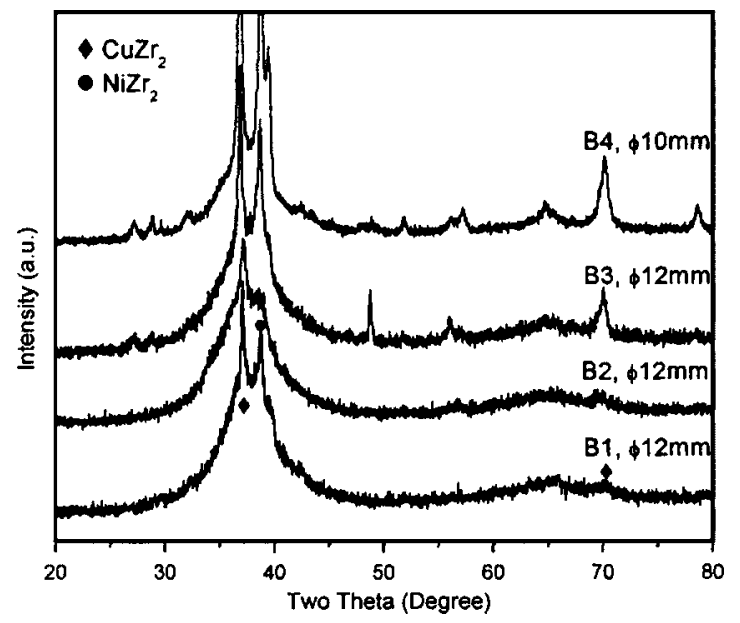

FIG. 4. XRD patterns obtained from as-cast rods with diameters of $12 \mathrm{~mm}$ for alloys B1 $\left(\left(\mathrm{Zr}_{56.2} \mathrm{Cu}_{31.3} \mathrm{Ni}_{4.0} \mathrm{Al}_{8.5}\right)_{93.9} \mathrm{Ti}_{6.1}\right), \quad$ B2 $\left(\mathrm{Zr}_{56.2} \mathrm{Cu}_{26.6} \mathrm{Ni}_{4.0} \mathrm{Al}_{8.5} \mathrm{Ti}_{4.7}\right)$, B3 $\left(\mathrm{Zr}_{56.2} \mathrm{Cu}_{31.3} \mathrm{Ni}_{3.3} \mathrm{Al}_{8.5} \mathrm{Ti}_{0.7}\right)$, and $10 \mathrm{~mm}$ for

alloy B4 $\left(\mathrm{Zr}_{56.2} \mathrm{Cu}_{31.3} \mathrm{Ni}_{4,0} \mathrm{Al}_{7.2} \mathrm{Ti}_{1.3}\right)$. 
TABLE I. Critical casting diameter $\left(d_{\max }\right)$ of ZrTiCuNiAl alloys whose compositions are obtained by partially substituting Ti for each component (i.e., Zr, " $\mathrm{Zr}_{56.2} \mathrm{Cu}_{31.3} \mathrm{Ni}_{4.0} \mathrm{Al}_{8.5}$ ", $\mathrm{Cu}, \mathrm{Ni}$, and $\left.\mathrm{Al}\right)$ in a base alloy $\mathrm{Zr}_{56.2} \mathrm{Cu}_{31.3} \mathrm{Ni}_{4.0} \mathrm{Al}_{8.5}$. The optimum amount of Ti replacement $\left(\mathrm{X}_{0}\right)$ is determined by the thermodynamic calculations, which is corresponding to the maximum liquidus depression $\left(\Delta T_{d}\right)$ in each replacement scheme.

\begin{tabular}{|c|c|c|c|c|c|c|}
\hline $\begin{array}{c}\text { Alloy } \\
\text { designation }\end{array}$ & $\begin{array}{l}\text { Component to be } \\
\text { replaced by } \mathrm{Ti}\end{array}$ & $\begin{array}{c}T_{l} \\
(\mathrm{~K})\end{array}$ & $\begin{array}{l}\Delta T_{d} \\
(\mathrm{~K})\end{array}$ & $\begin{array}{c}\mathrm{X}_{0} \\
\text { (at.\%Ti) }\end{array}$ & Alloy composition & $\begin{array}{l}d_{\max } \\
(\mathrm{mm})\end{array}$ \\
\hline Base alloy & $\cdots$ & 1104 & $\cdots$ & $\cdots$ & $\mathrm{Zr}_{56.2} \mathrm{Cu}_{31.3} \mathrm{Ni}_{4.0} \mathrm{Al}_{8.5}$ & 6 \\
\hline $\mathrm{A}^{*}$ & $\mathrm{Zr}$ & 1002 & 102 & 4.9 & $\mathrm{Zr}_{51.3} \mathrm{Cu}_{31.3} \mathrm{Ni}_{4.0} \mathrm{Al}_{8.5} \mathrm{Ti}_{4.9}$ & $>14$ \\
\hline B1 & $" \mathrm{Zr}_{56.2} \mathrm{Cu}_{31.3} \mathrm{Ni}_{4.0} \mathrm{Al}_{8.5} "$ & 1023 & 81 & 6.1 & $\left(\mathrm{Zr}_{56.2} \mathrm{Cu}_{31.3} \mathrm{Ni}_{4.0} \mathrm{Al}_{8.5}\right)_{93.9} \mathrm{Ti}_{6.1}$ & $10-12$ \\
\hline $\mathrm{B} 2$ & $\mathrm{Cu}$ & 1058 & 46 & 4.7 & $\mathrm{Zr}_{56.2} \mathrm{Cu}_{26.6} \mathrm{Ni}_{4.0} \mathrm{Al}_{8.5} \mathrm{Ti}_{4.7}$ & $10-12$ \\
\hline B3 & $\mathrm{Ni}$ & 1068 & 36 & 0.7 & $\mathrm{Zr}_{56.2} \mathrm{Cu}_{31.3} \mathrm{Ni}_{3.3} \mathrm{Al}_{8.5} \mathrm{Ti}_{0.7}$ & $\sim 10$ \\
\hline B4 & $\mathrm{Al}$ & 1086 & 18 & 1.3 & $\mathrm{Zr}_{56.2} \mathrm{Cu}_{31.3} \mathrm{Ni}_{4.0} \mathrm{Al}_{7.2} \mathrm{Ti}_{1.3}$ & $<10$ \\
\hline
\end{tabular}

GFA. For instance, a $10 \mathrm{~mm}$ sample of alloy A2 (containing $6.5 \% \mathrm{Ti}$ ) exhibits a pattern of multiple and sharper crystalline peaks superimposed on the much-weakened diffraction background, indicating the presence of a considerable amount of crystalline phases.

Figure 3 depicts the DSC traces taken from 1 or $2 \mathrm{~mm}$ as-cast samples of alloys $\left(\mathrm{Zr}_{56.2-x} \mathrm{Ti}_{x} \mathrm{Cu}_{31.3} \mathrm{Ni}_{4.0} \mathrm{Al}_{8.5}\right.$, $x=0-9.0$ ), which typically showed a clear endothermic inflection characteristic of glass transition at temperatures $\left(T_{g}\right)$ ranging from 656 to $675 \mathrm{~K}$, followed by one or more pronounced exothermic peaks corresponding to single or multiple crystallization events, respectively. These further confirm the amorphous nature of the as-cast samples of these alloys.

Based on the XRD and DSC results, we find that the largest amorphous rod made from the base alloy is of $\sim 6 \mathrm{~mm}$ in diameter, while replacing $\mathrm{Zr}$ with $4.9 \% \mathrm{Ti}$ in the base alloy can effectively increase the critical casting diameter, by a factor of at least 2.3, up to $14 \mathrm{~mm}$. And this is not the upper bound of the critical casting diameter for this alloy due to the limitation of our current casting apparatus. However, as shown in Fig. 1(a), the critical casting diameter substantially diminishes when more Ti was added, e.g. dropping down to $1 \mathrm{~mm}$ at $9.0 \% \mathrm{Ti}$, until it eventually vanishes at a critical $\mathrm{Ti}$ concentration of $10.0 \%$. Figure 1 demonstrates clearly that alloy $\mathrm{A}^{*}$, possessing the minimum liquidus temperature (or the maximum liquidus depression), is the bulkiest glass former in the series $\mathrm{Zr}_{56.2-x} \mathrm{Ti}_{x} \mathrm{Cu}_{31.3} \mathrm{Ni}_{4.0} \mathrm{Al}_{8.5}(x$ $=0-12$ ) as expected from our thermodynamic calculations.

Similarly, we also calculated the isopleths where-as usually done in experiments- $\mathrm{Ti}$ was used to replace, separately, the other components, e.g., $\mathrm{Cu}, \mathrm{Ni}, \mathrm{Al}$, or " $\mathrm{Zr}_{56.2} \mathrm{Cu}_{31.3} \mathrm{Ni}_{4.0} \mathrm{Al}_{8.5}$ " in the base alloy $\mathrm{Zr}_{56.2} \mathrm{Cu}_{31.3} \mathrm{Ni}_{4.0} \mathrm{Al}_{8.5}$. Here, " $\mathrm{Zr}_{56.2} \mathrm{Cu}_{31.3} \mathrm{Ni}_{4.0} \mathrm{Al}_{8.5}$ " is treated as an individual "component" in the Ti replacement by maintaining the concentration ratio of $\mathrm{Zr}, \mathrm{Cu}, \mathrm{Ni}$, and $\mathrm{Al}$ as the same as in the base alloy. For comparison, Table I summarizes the calculated maximum liquidus depressions (compared with the base alloy) and the corresponding amount of Ti replacement for five replacement schemes. It is found that the maximum liquidus depression $\left(\Delta T_{d}\right)$ ranges from $102 \mathrm{~K}$ in the case of $\mathrm{Ti}$ replacing $4.9 \% \mathrm{Zr}$ down to $18 \mathrm{~K}$ for $\mathrm{Ti}$ replacing $1.3 \% \mathrm{Al}$. Moreover, the calculated liquidus depression per unit amount of the $\mathrm{Ti}$ replacement of $\mathrm{Zr}$, i.e., $\sim 21 \mathrm{~K} /$ at. $\% \mathrm{Ti}$, indicates that replacing $\mathrm{Zr}$ with $\mathrm{Ti}$ is very effective in depressing the liquidus temperature of the base alloy. In other words, the relative thermodynamic stability of the liquid when compared with its competing crystalline phases is the greatest for replacement of $\mathrm{Zr}$ with Ti. Therefore, we further expect that alloy $\mathrm{A}^{*}$ would have the best GFA among all these five replacement schemes as listed in Table I. To verify this expectation, we examined experimentally the critical casting diameters for the alloys whose compositions are corresponding to the maximum liquidus depressions in the other four replacement methods (i.e., B1, B2, B3, and B4) as in Table I. However, none of these alloys is able to yield a $14 \mathrm{~mm}$ diameter amorphous rod using copper mold casting method (as indicated by their XRD patterns shown in Fig. 4), albeit they do form $6 \mathrm{~mm}$ diameter glassy rods, like the Ti-free quaternary base alloy. These findings assure us that the alloy composition obtained from replacing $\mathrm{Zr}$ with $4.9 \% \mathrm{Ti}$ in the base alloy is the best BMG former, not only in the series of alloys $\mathrm{Zr}_{56.2-x} \mathrm{Ti}_{x} \mathrm{Cu}_{31.3} \mathrm{Ni}_{4.0} \mathrm{Al}_{8.5}(x=0-10)$, but also among those generated by the replacement methods as listed in Table I. In this regard, our computational thermodynamic strategy is proving to be robust in locating the bulkiest BMG former with optimum minor-alloying additions. Obviously, this strategy can be readily extended to other potential alloy systems to develop new families of bulk metallic glasses with minimum of experimental investigations.

This work is supported by DARPA under ARO Contract No. DAAD 19-01-1—525, and the Wisconsin Distinguished Professorship.

${ }^{1}$ D. Xu, G. Duan, and W. L. Johnson, Phys. Rev. Lett. 92, 245504 (2004). ${ }^{2}$ Z. P. Lu, C. T. Liu, J. R. Thompson, and W. D. Porter, Phys. Rev. Lett. 92, 245503 (2004)

${ }^{3}$ D. B. Miracle, Nat. Mater. 3, 697 (2004).

${ }^{4}$ R. L. Mcgreevy, Nucl. Instrum. Methods Phys. Res. A 354, 1 (1995).

${ }^{5}$ P. Jalali and M. Li, Phys. Rev. B 71, 014206 (2005).

${ }^{6}$ Y. A. Chang, S. Chen, F. Zhang, X. Yan, F. Xie, R. Schmid-Fetzer, and W. A. Oates, Prog. Mater. Sci. 49, 313 (2004).

${ }^{7}$ D. Turnbull, Contemp. Phys. 10, 473 (1969).

${ }^{8}$ Z. P. Lu and C. T. Liu, Phys. Rev. Lett. 91, 115505 (2003).

${ }^{9}$ A. Masuhr, T. A. Waniuk, R. Busch, and W. L. Johnson, Phys. Rev. Lett. 82, 2290 (1999).

${ }^{10}$ S.-L. Chen, S. Daniel, F. Zhang, Y. A. Chang, W. A. Oates, and R. Schmid-Fetzer, J. Phase Equilib. 22, 373 (2001).

${ }^{11}$ X. Y. Yan, Y. A. Chang, Y. Yang, F. Y. Xie, S. L. Chen, F. Zhang, S. Daniel, and M. H. He, Intermetallics 9, 535 (2001). 